\title{
Fusion and stereopsis in children with refractive amblyopia
}

\section{Fusión y estereopsis en niños con ambliopía refractiva}

\author{
Lourdes R. Hernández-Santos ${ }^{1 *}$, Taimí Cárdenas-Díaz ${ }^{1}$, Teresita de J. Méndez-Sánchez ${ }^{1}$, \\ Pedro D. Castro-Pérez ${ }^{2}$, and Lucy Pons-Castro ${ }^{1}$ \\ ${ }^{1}$ Department of Ophthalmology; ${ }^{2}$ Department of Comprehensive General Medicine. Instituto Cubano de Oftalmología Ramón Pando Ferrer, Havana \\ city, Cuba
}

\begin{abstract}
Objective: To determine the binocular function in patients with refractive amblyopia. Method: Cross-sectional study in patients between 5 and 18 years old with refractive amblyopia treated for the first time in the pediatric ophthalmology and strabismus consultation of the Instituto Cubano de Oftalmología Ramón Pando Ferrer. Results: No significant correlation was found between the depth of amblyopia and the magnitude of anisometropia in the right eye $(p=0.217)$ or in the left eye $(p=-0.130)$, and neither between the magnitude of anisometropia and stereopsis $(p=0.260)$. Patients with isoametropic amblyopia reached a subnormal stereopsis $>100$ " in $53.3 \%$. Conclusions: There is no association between the magnitude of anisometropia and the depth of amblyopia, fusion and stereopsis. In most patients with refractive amblyopia, stereopsis is deteriorated, thus affecting binocular function.
\end{abstract}

Keywords: Amblyopia Anisometropia. Isoametropia. Stereopsis. Fusion.

\section{Resumen}

Objetivo: Determinar la función binocular en pacientes con ambliopía refractiva. Método: Estudio transversal en pacientes entre 5 y 18 años con ambliopía refractiva atendidos por vez primera en la consulta de oftalmología pediátrica y estrabismo del Instituto Cubano de Oftalmología Ramón Pando Ferrer. Resultados: No se halló correlación significativa entre la profundidad de la ambliopía y la magnitud de la anisometropía en el ojo derecho $(p=0.217)$ ni en el ojo izquierdo $(p=-0.130)$, y tampoco entre la magnitud de la anisometropía y la estereopsis $(p=0.260)$. El $53.3 \%$ de los pacientes con ambliopía isoametrópica alcanzaron una estereopsis subnormal > 100". Conclusiones: No se presenta asociación entre la magnitud de la anisometropía y la profundidad de la ambliopía, la fusión y la estereopsis. En la mayoría de los pacientes con ambliopía refractiva se deteriora la estereopsis, afectándose así la función binocular.

Palabras clave: Ambliopía. Anisometropía. Isoametropía. Estereopsis. Fusión.

\section{Introduction}

Amblyopia is derived from the Greek word amblys, which means "lazy, clumsy" and ops, meaning "eye" for what is commonly called "lazy eye".
Over the years it has had numerous definitions ${ }^{2-6}$ according to the different authors and the study objectives, but the vast majority agree that amblyopia is "a visual deficit with no organic or anatomical cause to justify it."

Correspondence:

*Lourdes R. Hernández-Santos

Avda. 76, 3104

Date of reception: 15-05-2021

Date of acceptance: 04-08-2021

Marianao, 11500, Havana city, Cuba

E-mail: lourdesrita@infomed.sld.cu

2604-1731/๑ 2021 Sociedad Mexicana de Oftalmología. Published by Permanyer. This is an open access article under the CC BY-NC-ND license (http://creativecommons.org/licenses/by-nc-nd/4.0/). 
An uncorrected refractive error is the main cause of visual impairment $(43 \%)$, followed by cataract $(39 \%)^{7}$. An early and undiagnosed refractive error in early childhood can lead to a reduction in visual acuity. Visual development is a process that requires adequate visual stimulation in the first years of life, which can be interrupted by the presence of non-physiological refractive disorders that produce a blurred image, favoring the development of refractive amblyopia. The detection of refractive errors from an early age is important to make the decision on whether or not to prescribe the refraction, for which the age and amount of the refractive error must be taken into account, based on correction guidelines that vary according to different authors ${ }^{2,3-8}$.

Naidoo, et al. ${ }^{9}$ point out that uncorrected refractive errors were the cause of visual impairment in 101.2 million people and $6.8 \%$ of blindness in 2010 .

It is estimated that worldwide there are $\mathbf{2 8 5}$ million people with some type of visual impairment, of which 19 million are children under 14 years of age $\mathrm{e}^{7,10}$. A total of 153 million people in the world have visual disturbances secondary to uncorrected refractive errors, and of these, 12.8 million are children between the ages of 5 and $15^{10}$.

Binocular single vision is the state of simultaneous vision, achieved by the coordinated use of both eyes, from two retinal images that are fused by motor and sensory processes that culminate in the perception of a single image in stereoscopic depth. The main advantage of binocular vision is the single vision that results in stereopsis ${ }^{11}$.

Binocular single vision is divided into three degrees of fusion ${ }^{1,12}$ :

- First degree: simultaneous macular perception, in which both eyes receive the image at the same time.

- Second degree: fusion (ability of the visual cortex to fuse the images received by each eye into a single image); it can be sensory or motor.

- Third degree: stereopsis.

To evaluate the state of binocular function, fusion and stereopsis are considered. In the case of fusion (second degree of binocular vision), Worth's lights are used, and for the exploration of stereopsis (third degree of binocular vision), the Titmus test.

Achieving quality vision not only depends on achieving 20/20 visual acuity in distance vision, but also on having good contrast vision and adequate stereopsis. Stereopsis enables simple depth perception and is considered the only property of binocular vision that allows the perception of depth and solidity in visual space. In people with normal visual acuity, it is around 40 or $60 " 13$.

As levels of anisometropia vary, suppression and stereopsis change. Normal development allows good binocular vision. Blurred vision at an early age causes a particular pattern of functional loss that leads to subnormal binocular vision.

The objective of this study was to determine binocular function in patients with refractive amblyopia, relating the magnitude of anisometropia with the depth of amblyopia, fusion and stereopsis, as well as determining fusion and stereopsis in patients with isoametropic amblyopia.

\section{Methods}

A cross-sectional study was carried out in 27 patients (54 eyes) with refractive amblyopia who were taken by their parents for the first time to the pediatric ophthalmology and strabismus department of the Instituto $\mathrm{Cu}$ bano de Oftalmología Ramón Pando Ferrer, during the period between July and December of 2019. The small sample size was due to the inclusion and exclusion criteria, as the research was affected by the COVID-19 pandemic.

We included children between 5 and 18 years old, whose legal guardians voluntarily agreed to participate in the study, with a best-corrected visual acuity (BCVA) of 20/30 (0.18 logMAR) or less in one or both eyes, or a difference of at least 2 logMAR lines, that had not previously received any prescription, with the following refractive errors: myopia $\leq-0.50 \mathrm{D}$, hyperopia $\geq 0.50$, astigmatism $\geq 0.50 \mathrm{D}$ and anisometropia $\geq 1 \mathrm{D}$. Patients with allergy to cycloplegics, presence of any ocular disorder that decreased visual acuity (surgical aphakia, pediatric cataract, palpebral ptosis), mental retardation, infantile cerebral palsy or Down syndrome were excluded.

Amblyopia was divided by type into isoametropic ( $\mathrm{Al}$, refractive error of equal magnitude in both eyes) and anisometropic (AA, interocular difference of spherical or cylindrical refractive error of $1 \mathrm{D}$ or more $)^{14}$.

Depth of amblyopia was based on BCVA measured with the Snellen chart and converted to logMAR. The classification scale used was: mild, 20/30-20/40 (0.180.30 logMAR); moderate, $>20 / 40-20 / 80$ (0.30-0.60 logMAR); and severe, $>20 / 80(0.60 \text { logMAR })^{3}$.

The magnitude of anisometropia was classified as mild, 1.00-3.00 D; high, >3.00-6.00 D; and very high, $>6.00 \mathrm{D}^{15}$. 
For stereopsis evaluation, the Titmus test (Stereo Optical Co., Inc., Chicago, IL, USA) was used, despite the monocular cues, as it is easier to interpret in children. Stereopsis was examined at near distance $(40 \mathrm{~cm})$, with optical correction and polarized glasses, and it was classified as normal up to 40", subnormal $>40-100 "$ and abnormal $>100 "$ ", according to the classification used by Sapkota ${ }^{16}$.

Fusion was explored with Worth four light test (Worth 4-Dot Attachment, Richmond Products, Albuquerque, $\mathrm{NM}$, USA), at $6 \mathrm{~m}$, with red-green lenses (Original Bernell Model Red/Green Goggles; Bernell VTP, Mishawaka, IN, USA), over the corrected refractive defect. We established sensory fusion if the patient saw all four lights and suppression if they saw three green lights or two red lights.

To carry out this work, data from the patient's medical records were taken. The information was entered by the primary investigator in a spreadsheet prepared for this purpose.

The study began by intervewing patients, specifying age, previous ocular consultations and treatments, followed by the determination of BCVA and performance of the alternate cover test and the near and far cover-uncover test with an accommodative target to detect any deviation in primary gaze position.

Subsequently, the cycloplegic refraction was evaluated with a TOPCON KR8800 Auto Kerato-Refractometer, a trial box and frame, and finally corroborating the refraction by retinoscopy.

Finally, biomicroscopic examination of the anterior segment and indirect ophthalmoscopy were performed to assess the optic disc, the retinal vessels and the macula, and rule out any ocular alteration that may affect visual acuity.

Seven days after the first visit, BCVA was verified with the Snellen chart and converted into logMAR according to the visual acuity conversion chart, and patients with a visual acuity of $20 / 30$ or less ( $0.18 \log M A R)$ in one or both eyes were selected.

The aforementioned process was carried out in each patient who participated in the study, in order to obtain the refractive defect at the time of entry in the database, to classify it and define the type of amblyopia.

With the refractive defect corrected, the study of stereopsis and fusion was carried out.

After collecting primary data, they were organized in Microsoft Excel to later be exported to the SPSS version 22 program. The variables that were measured in a nominal and ordinal way were expressed in absolute and relative frequency, while for the
Table 1. Distribution of the eyes according to the depth and type of amblyopia

\begin{tabular}{l|c|c|c|c|}
\hline $\begin{array}{l}\text { Depth of } \\
\text { amblyopia }\end{array}$ & \multicolumn{2}{|c|}{$\begin{array}{c}\text { Anisometropic } \\
\text { amblyopia }(n=12)\end{array}$} & \multicolumn{2}{c|}{$\begin{array}{c}\text { Isoametropic } \\
\text { amblyopia }(n=15)\end{array}$} \\
\cline { 2 - 5 } OD (\%) & OS (\%) & OD (\%) & OS (\%) \\
\hline Mild & $1(8.3 \%)$ & $5(41.7 \%)$ & $11(73.3 \%)$ & $11(73.3 \%)$ \\
\hline Moderate & $2(16.7 \%)$ & $4(33.3 \%)$ & $4(26.7 \%)$ & $4(26.7 \%)$ \\
\hline Severe & $2(16.7 \%)$ & $0(0 \%)$ & $0(0 \%)$ & $0(0 \%)$ \\
\hline Total & $5(41.7 \%)$ & $9(75.0 \%)$ & $15(100 \%)$ & $15(100 \%)$ \\
\hline
\end{tabular}

OD: right eye; OS: left eye.

metrics the mean, standard deviation and the minimum and maximum values were determined. Spearman's rank correlation coefficient (rho) and contingency coefficient $(C)$ were applied, and a confidence level of $95 \%$ was defined $(p=0.05)$.

The bioethical principles were met (in accordance with the provisions of the National Health System and provided for in Law No. 41 on Public Health) and the study was approved by the scientific and ethics committees of the Instituto Cubano de Oftalmología Ramón Pando Ferrer, in accordance with the principles of the Declaration of Helsinki. For the development of the study, we obtained the informed consent of the guardians of the children who participated in the research, a document in which the principles of benefit of the procedure and legality of the work are exposed, as well as the autonomy of the patients to decide to participate or withdraw from the study.

\section{Results}

Of the 27 children with amblyopia included in the study, Al was found in $15(55.6 \%)$ and AA in $12(44.4 \%)$.

Table 1 shows the distribution of the eyes according to the depth and type of amblyopia. In AA, a predominance of left amblyopic eyes is observed (nine for $75 \%$ ), of which five showed mild amblyopia and four moderate, for $41.7 \%$ and $33.3 \%$, respectively. In the five amblyopic right eyes, a similar distribution of moderate and severe amblyopia was observed, in two eyes each, for $16.7 \%$; only one eye (8.3\%) had mild amblyopia.

In Al, mild amblyopia prevailed in 11 right eyes and 11 left eyes, with $73.3 \%$, followed by moderate in four right and left eyes, for $26.7 \%$.

Table 2 shows the distribution of right and left eyes according to anisometropía magnitude and 
Table 2. Distribution according to the magnitude of anisometropia and depth of amblyopia

\begin{tabular}{|c|c|c|c|c|c|c|c|c|}
\hline \multirow[t]{3}{*}{ Depth of amblyopia } & \multicolumn{8}{|c|}{ Magnitude of anisometropia } \\
\hline & \multicolumn{2}{|c|}{ Mild } & \multicolumn{2}{|c|}{ High } & \multicolumn{2}{|c|}{ Very high } & \multicolumn{2}{|c|}{ Total } \\
\hline & OD & OS & OD & OS & OD & OS & OD & OS \\
\hline $\begin{array}{l}\text { Mild } \\
\quad n \\
\%\left(n_{3}\right) \\
\%\left(n_{1}\right)\end{array}$ & $\begin{array}{c}1 \\
20 \\
8.3\end{array}$ & $\begin{array}{c}5 \\
55.5 \\
41.7\end{array}$ & $\begin{array}{c}0 \\
0.0 \\
0.0\end{array}$ & $\begin{array}{c}0 \\
0.0 \\
0.0\end{array}$ & $\begin{array}{c}0 \\
0.0 \\
0.0\end{array}$ & $\begin{array}{c}0 \\
0.0 \\
0.0\end{array}$ & $\begin{array}{c}1 \\
20 \\
8.3\end{array}$ & $\begin{array}{c}5 \\
55.5 \\
41.7\end{array}$ \\
\hline $\begin{array}{l}\text { Moderate } \\
\text { n } \\
\%\left(n_{3}\right) \\
\%\left(n_{1}\right)\end{array}$ & $\begin{array}{c}1 \\
20 \\
8.3\end{array}$ & $\begin{array}{c}2 \\
22.2 \\
16.7\end{array}$ & $\begin{array}{c}1 \\
20 \\
8.3\end{array}$ & $\begin{array}{c}2 \\
22.2 \\
16.7\end{array}$ & $\begin{array}{c}0 \\
0.0 \\
0.0\end{array}$ & $\begin{array}{c}0 \\
0.0 \\
0.0\end{array}$ & $\begin{array}{c}2 \\
40 \\
16.7\end{array}$ & $\begin{array}{c}4 \\
44.4 \\
33.3\end{array}$ \\
\hline $\begin{array}{l}\text { Severe } \\
\mathrm{n} \\
\%\left(n_{3}\right) \\
\%\left(n_{1}\right)\end{array}$ & $\begin{array}{c}1 \\
20 \\
8.3\end{array}$ & $\begin{array}{c}0 \\
0.0 \\
0.0\end{array}$ & $\begin{array}{c}0 \\
0.0 \\
0.0\end{array}$ & $\begin{array}{c}0 \\
0.0 \\
0.0\end{array}$ & $\begin{array}{c}1 \\
20 \\
8.3\end{array}$ & $\begin{array}{c}0 \\
0.0 \\
0.0\end{array}$ & $\begin{array}{c}2 \\
40 \\
16.7\end{array}$ & $\begin{array}{c}0 \\
0.0 \\
0.0\end{array}$ \\
\hline $\begin{array}{l}\text { Total } \\
\text { n } \\
\%\left(n_{3}\right) \\
\%\left(n_{1}\right)\end{array}$ & $\begin{array}{c}3 \\
60 \\
25\end{array}$ & $\begin{array}{c}7 \\
77.8 \\
58.3\end{array}$ & $\begin{array}{c}1 \\
20 \\
8.3\end{array}$ & $\begin{array}{c}2 \\
22.2 \\
16.7\end{array}$ & $\begin{array}{c}1 \\
20 \\
8.3\end{array}$ & $\begin{array}{c}0 \\
0.0 \\
0.0\end{array}$ & $\begin{array}{c}5 \\
100 \\
41.7\end{array}$ & $\begin{array}{c}9 \\
100 \\
75\end{array}$ \\
\hline
\end{tabular}

OD: right eye; OS: left eye.

$\mathrm{n1}$ : total number of patients with anisometropic amblyopia (12); n3: total number of eyes with anisometropic amblyopia (5 for right eye and 9 for left eye).

Table 3. Distribution of patients according to the magnitude of anisometropia and fusion

\begin{tabular}{|c|c|c|c|c|}
\hline \multirow[t]{3}{*}{ Fusión } & \multicolumn{3}{|c|}{ Magnitud de la anisometropía } & \multirow{3}{*}{$\frac{\text { Total }}{\text { n ( } \%)}$} \\
\hline & Mild & High & Very high & \\
\hline & $n(\%)$ & $n(\%)$ & $n(\%)$ & \\
\hline Sensory fusion & $8(66.7 \%)$ & $2(16.7 \%)$ & $1(8.3 \%)$ & $11(91.7 \%)$ \\
\hline Supression & $0(0 \%)$ & $1(8.3 \%)$ & $0(0 \%)$ & $1(8.3 \%)$ \\
\hline Total $\left(n_{1}=12\right)$ & $8(66.7 \%)$ & $3(25.0 \%)$ & $1(8.3 \%)$ & $12(100 \%)$ \\
\hline
\end{tabular}

$\mathrm{n}_{1}$ : total number of patients with anisometropic amblyopia (12 for right eye and left eye).

amblyopia type. Of the five amblyopic right eyes, three had a magnitude of mild anisometropia $<3.00$ $D$, one moderate and the other one severe $(20 \%$ each). One eye with a high magnitude of anisometropia had moderate amblyopia, and the eye with a very high magnitude (> $6.00 \mathrm{D}$ ) had severe amblyopia (20\%). Of the seven left eyes, five $(55.5 \%)$ had a mild magnitude of anisometropia and two $(22.2 \%)$ moderate. However, the two eyes with high magnitude had moderate amblyopia. No statistically significant correlation was observed between the depth of amblyopia and the magnitude of anisometropia in right eye (rho $=0.249 ; p=0.217$ ), nor in the left eye (rho $=0.344 ; p=-0.130$ ).

The binocular function evaluated in these patients included fusion and stereopsis. Tables 3 and 4 show that there was fusion in all patients except in one 9 -year-old with high anisometropia, who had subnormal stereopsis (between 40" and 100"); however, the patient with very high anisometropia had fusion and abnormal stereopsis. In these patients, no statistically significant correlation was observed between the magnitude of AA and fusion with the contingency coefficient test $(C=0.463 ; p=0.195)$, or between the magnitude of $A A$ and the level of stereopsis with the Spearman's correlation test ( $r$ ho $=0.206$; $p=0.260)$.

Table 5 shows that, of the 15 patients with Al, eight (53.3\%) had a subnormal stereopsis $>100$ ". Of them, five had a high refractive error, two moderate and one mild; the latter was a patient with mild astigmatism who had an elevated spherical equivalent of 8.13 . 
Table 4. Distribution of patients according to the magnitude of anisometropia and stereopsis

\begin{tabular}{|c|c|c|c|c|}
\hline \multirow[t]{3}{*}{ Estereopsis } & \multicolumn{3}{|c|}{ Magnitude of anisometropia } & \multirow{3}{*}{$\begin{array}{c}\text { Total } \\
\text { n (\%) }\end{array}$} \\
\hline & Mild & High & Very high & \\
\hline & $n(\%)$ & $n(\%)$ & $n(\%)$ & \\
\hline Normal $<40 "$ & $2(16.7 \%)$ & $0(0 \%)$ & $0(0 \%)$ & $2(16.7 \%)$ \\
\hline Subnormal $40-100 "$ & $1(8.3 \%)$ & $1(8.3 \%)$ & $0(0 \%)$ & $2(16.7 \%)$ \\
\hline Anormal > 100" & $5(41.7 \%)$ & $2(16.7 \%)$ & $1(8.3 \%)$ & $8(66.7 \%)$ \\
\hline Total $\left(n_{1}=12\right)$ & $8(66.7 \%)$ & $3(25.0 \%)$ & $1(8.3 \%)$ & $12(100 \%)$ \\
\hline
\end{tabular}

Table 5. Fusion and stereopsis in isoametropic amblyopia

\begin{tabular}{|c|c|}
\hline & $\begin{array}{c}\text { Isoametropic amblyopia }(n=15) \\
n(\%)\end{array}$ \\
\hline $\begin{array}{l}\text { Fusion } \\
\text { Sensory fusion }\end{array}$ \\
$\begin{array}{l}\text { Supression } \\
\text { Total }\end{array}$ \\
\hline Stereopsis & $15(100 \%)$ \\
Normal $<40 "$ & $0(0 \%)$ \\
Subnormal 40-100" & $15(100 \%)$ \\
Abnormal > 100" & \\
Total & $1(6.67 \%)$ \\
\hline
\end{tabular}

\section{Discussion}

In this study, we observed that the mean age at the first consultation was 8 years for AA and 6.73 years for $\mathrm{Al}$, which is considered a late age, since it is almost at the end of the period of sensitivity, which is up to 8 years. This is due to a carelessness of the parents, since the country has an ophthalmological examination system from birth that includes a complete ophthalmological examination at birth, at 6 months, and at 1, 3 and 5 years before starting the school year, which is repeated every 2 years and varies according to the criteria of the ophthalmologist who does the examination.

Regarding the prevalence of amblyopia according to the degree of depth, Istek ${ }^{14}$ found moderate amblyopia $(59.4 \%)$ more frequently, followed by severe $(31.2 \%)$ and mild $(9.4 \%)$. Sapkota ${ }^{16}$ found a predominance of severe amblyopia (46\%), followed by moderate $(41 \%)$, without finding a statistically significant association between the depth of amblyopia and the type of refractive error. This is not consistent with what we found in our study, where mild and moderate amblyopia predominated in $\mathrm{AA}$, and mild amblyopia was predominant in $\mathrm{Al}$.
Some studies have not found an association between the magnitude of anisometropia and the depth of amblyopia $^{17-19}$, which coincides with our study, in which when comparing the depth of amblyopia with the magnitude of anisometropia in patients with AA in the right and left eyes, no significant correlation was found $(p=0.217$ and $p=0.344$, respectively).

Sapkota $^{16}$ and Rutstein and Corliss ${ }^{20}$ found that the depth of amblyopia was related to the magnitude of anisometropia: the greater the magnitude of the anisometropia, the greater the risk of severe amblyopia.

Istek ${ }^{14}$ found that a difference in refractive error of 0.75 for astigmatism between both eyes or 1.50 for spherical defect was enough to develop amblyopia.

Binocular vision is important in the visual perception of the environment. Stereopsis occurs when images with horizontal disparity are placed in corresponding retinal areas in each eye simultaneously, and the fusion of those images results in stereoscopic acuity with depth perception.

Normal visual neurodevelopment is not established if there is a condition that interferes with binocular sensory fusion, such as a refractive error that causes blurring of the retinal image and if this condition occurs early.

Decreased binocular sensory fusion presents clinically as suppression or reduced stereoacuity ${ }^{21}$.

Chen, et al..$^{15}$ suggest that binocular function, including fusion and stereopsis, decreases markedly as the magnitude of anisometropia increases. This may be associated with aniseiconia, which interferes with binocular vision. A degree of anisometropia $>3.00 \mathrm{D}$ resulted in suppression and subnormal stereopsis $>40-100$. With an anisometropia $>6.00 \mathrm{D}$, only $16.67 \%$ had fusion and $8.33 \%$ stereopsis, being the latter more severely affected.

Jeon and $\mathrm{Choi}^{22}$ point out that stereopsis was significantly worse in the group with anisometropic amblyopia 
(AA) than with anisometropia without amblyopia (NA) and in the control group; only $57.2 \%$ had a normal stereopsis in the AA group. They found a significant relationship between the degree of anisometropia and the level of stereopsis in amblyopic and non-amblyopic anisometropic patients $(p=0.028)$; however, the group with amblyopia did not show a significant correlation between the degree of anisometropia and the level of stereopsis $(p=0.692)$.

Tomac and Birdal ${ }^{23}$ demonstrated the relationship between stereoacuity and the strength of fusion, and they state that, if fusion is weak, stereopsis decreases in proportion to the amblyopia; only $14.3 \%$ of the group with amblyopia had sensory fusion.

Rutstein and Corliss $^{20}$, and Jeon and $\mathrm{Choi}^{22}$ found that AA patients have better binocular function than that reported by experimental studies such as that of Brooks, et al. ${ }^{24}$.

Levi, et al. ${ }^{25}$ found that binocular function develops normally in anisometropies $<3.00 \mathrm{D}$, but in $>3 \mathrm{D}$, and mainly in $>6.00 \mathrm{D}$, fusion and stereopsis are seriously affected.

This is consistent with experimental studies that indicate that $1 \mathrm{D}$ anisometropia reduces stereoscopic visual acuity from 40 "to 85 ", and $3 \mathrm{D}$ anisometropia produces a marked reduction in stereopsis in all subjects.

Yang, et al. ${ }^{26}$ found that hyperopia or a spherical equivalent $>+3.00 \mathrm{D}$ is associated with a reduction in stereoacuity in the Titmus test, but this is not the case with spherical or astigmatic anisometropia.

In another study in preschool children, it was shown that a large percentage of patients with anisometropia had worse stereoacuity ${ }^{18,27}$; however, in a more recent study, Lee, et al. ${ }^{28}$ found an almost normal level of stereopsis in patients with anisometropia without amblyopia using their optical correction, suggesting that optical correction is the best treatment option to ensure optimal visual development in these children.

In this study, it was observed that in AA, binocular function does not develop normally in anisometropia $<3.00 \mathrm{D}$, since from the eight $(66.77 \%)$ patients who were in the mild group, five (41.7\%) had an abnormal stereopsis $>100$ ". Of the three patients with high magnitude AA, two had an abnormal stereopsis and one a subnormal stereopsis between 40 " and 100". The only patient with high magnitude AA had a stereopsis $>100$ ". There was no significant correlation between the magnitude of $A A$ and fusion ( $p=0.195)$, nor between the magnitude of $A A$ and stereopsis $(p=0.260)$.
In the Al group, despite not having fusion alterations in any patient, eight had an abnormal stereopsis $<100$ ".

Differences in results with other studies may be related to the small number of patients and the short time for participants selection. In this study, no association was found between the magnitude of $A A$ and the depth of amblyopia, fusion, and stereopsis, and in most patients with refractive amblyopia, stereopsis was deteriorated and binocular function was affected.

\section{Funding}

The authors declare that there was no funding from any institution.

\section{Conflicts of interest}

The authors declare no conflicts of interest.

\section{Ethical disclosures}

Protection of human and animal subjects. The authors declare that the procedures followed were in accordance with the regulations of the relevant clinical research ethics committee and with those of the Code of Ethics of the World Medical Association (Declaration of Helsinki).

Confidentiality of data. The authors declare that they have followed the protocols of their work center on the publication of patient data.

Right to privacy and informed consent. The authors have obtained the written informed consent of the patients or subjects mentioned in the article. The corresponding author is in possession of this document.

\section{References}

1. Lam ME, Villa VA. Frecuencia de ambliopía en alumnos de 6 a 8 años de la unidad educativa Hermano Miguel "La Salle", Cuenca, Ecuador, 2016. [Tesis]. Universidad de Cuenca, Ecuador; 2017.

2. American Academy of Ophthalmology. Basic and Clinical Science Course. Pediatric ophthalmology and strabismus: Section 6, 2019-2020. San Francisco, CA: American Academy of Ophthalmology; 2019.

3. American Academy of Ophthalmology. Preferred practiced pattern. [citado 3 de diciembre de 2017]. Disponible en: https://www.aao.org/preferred-practicepattern/amblyopia-ppp-2017.

4. Huang D, Chen X, Zhu H, Ding H, Bai J, Chenet J, et al. Prevalence of amblyopia and its association with refraction in Chinese preschool children aged 36-48 months. Br J Ophthalmol. 2018;102:767-71.

5. Ortiz Barrantes R, Goñi-Boza E. Conceptualización integral de la ambliopía. Cienc Tecnol Salud Vis Ocul. 2018;16:91-8.

6. Sloper J. The other side of amblyopia. J AAPOS. 2016;20:e1

7. Olusanya BA, Ugalahi MO, Ogunleye OT, Baiyeroju AM. Refractive errors among children attending a tertiary eye facility in Ibadan, Nigeria: highlighting the need for school eye health programs. Ann lb Postgrad Med. 2019;17:49-59.

8. Rouse M. Optometric clinical practice guideline - care of the patient with amblyopia. 2004. Disponible en: http://www.aoa.org/documents/ CPG-4.pdf 
9. Naidoo KS, Leasher J, Bourne RR, Flaxman S, Jonas J, Keeffe J, et al. Global vision impairment and blindness due to uncorrected refractive errors, 1990-2010. Optom Vis Sci. 2016;93:227-34.

10. Al-Tamimi ER, Shakeel A, Yassin SA, Ali SI, Khan UA. A clinic-based study of refractive errors, strabismus, and amblyopia in pediatric agegroup. Fam Commun Med. 2015;22:158-62.

11. Skalicky SE. Binocular single vision and stereopsis. Ocular and visual physiology. Singapore: Springer; 2016. p. 355-66.

12. Batool A, Bhatti RI, Fatima SM, Zehra T, Liaquat M. Effect of amblyopia on grades of binocular single vision. Ophthalmol Vis Sci. 2019;3:28-38.

13. Han E, Duckman RH. Clinical tests of fusion and stereopsis. 2003. [citado 5 junio 2016]. Disponible en: https://entokey.com/clinical-tests-of-fusion-and-stereopsis

14. Istek S. Anisometropia magnitude and amblyopia depth in previously untreated unilateral amblyopia patients. Open Access Library Journal. 2017;4:1-10.

15. Chen BB, Song FW, Sung ZH, Yang Y. Anisometropia magnitude and visual deficits in previously untreated anisometropic amblyopia. Int $J$ Ophthalmol. 2013;6:65-81.

16. Sapkota K. A retrospective analysis of children with anisometropic amblyopia in Nepal. Strabismus. 2014;22:47-51.

17. McConaghy JR, McGuirk R. Amblyopia: detection and treatment. Am Fam Physician. 2019;100:745-50.

18. Weakley DR. The Association between nonstrabismic anisometropia amblyopia, and subnormal binocularity. Ophthalmology. 2001;108 163-71.
19. Caputo R, Frosini R, De Libero C, Campa L, Magro EF, Secci J. Factors influencing severity of and recovery from anisometropic amblyopia. Strabismus. 2007;15:209-14.

20. Rutstein RP, Corliss D. Relationship between anisometropia, amblyopia, and binocularity. Optom Vis Sci. 1999;76: 229-33.

21. Webber AL, Camuglia JE. A pragmatic approach to amblyopia diagnosis: evidence into practice. Clin Exp Optom. 2018;101:451-9.

22. Jeon HS, Choi DG. Stereopsis and fusion in anisometropia according to the presence of amblyopia. Graefes Arch Clin Exp Ophthalmol. 2017;255:2487-92

23. Tomac S, Birdal E. Effects of anisometropia on binocularity. J Pediatr Ophthalmol Strabismus. 2001;38:27-33.

24. Brooks SE, Johnson D, Fischer N. Anisometropia and binocularity. Ophthalmology. 1996;103:1139-43.

25. Levi DM, McKee SP, Movshon JA. Visual deficits in anisometropia. Vision Res. 2011;51:48-57

26. Yang JW, Huang TY, Yang KJ, Lee YS, Ku WC, Yeung L, et al. The effects of hyperopic and astigmatic ametropia on stereoacuity by Titmus stereo test. Taiwan J Ophthalmol. 2012;2:22-4.

27. Ying GS, Huang J, Maguire MG, Quinn G, Kulp MT, Ciner E, et al. Associations of anisometropía with unilateral amblyopia, interocular acuity difference, and stereo acuity in preschoolers Ophthalmology. 2013;120:495-503.

28. Lee JY, Seo JY, Baek SU. The effects of glasses for anisometropia on stereopsis. Am J Ophthalmol. 2013;156:1261-6. 